\title{
Active ingredients, mechanisms of action and efficacy tests of antipollution cosmetic and personal care products
}

\author{
Maria Valéria Robles Velasco ${ }^{1 \S}$, Rafael Sauce ${ }^{1 \S}$, Camila Areias de Oliveira ${ }^{2}$, Claudinéia A.S. de \\ Oliveira Pinto ${ }^{1}$, Renata Miliani Martinez ${ }^{1}$, Stephanie Baah ${ }^{3}$, Tânia Santos Almeida ${ }^{4}$, Catarina \\ Rosado $^{4}$, André Rolim Baby ${ }^{1 *}$
}

\begin{abstract}
${ }^{1}$ Department of Pharmacy, School of Pharmaceutical Sciences, University of São Paulo, São Paulo, SP, Brazil, ${ }^{2}$ Department of Biochemical-Pharmaceutical Technology, School of Pharmaceutical Sciences, University of São Paulo, São Paulo, SP, Brazil, ${ }^{3}$ Pharmacy (MPharm3), King's College London, United Kingdom, ${ }^{4} \mathrm{CBIOS}$ - Universidade Lusófona 's Research Center for Biosciences and Health Technologies, Lisbon, Portugal
\end{abstract}

\begin{abstract}
Urban population around the globe is direct exposed to the pollution caused by several sources (vehicles, industries, smokes etc.) and primary pollutants are divided in particulate matter and toxic gases. Current researches in populous countries indicated that exposure to pollution could affect sebum composition, stratum corneum quality and signs of skin aging. Hair and scalp are also affected by the excessive exposure to pollutants, resulting in a dull, dry and lifeless appearance. Cosmetics have been evolved conceptual and scientifically to achieve substantial effectiveness against pollution damaging on the cutaneous tissue, involving the development of innovative multipurpose active ingredients and efficacy tests, skilled to prove the protection and benefits of such personal care products. In this review, we highlighted the skin and hair/scalp damages provoked by the main environmental pollutants and the active substances used in antipollution cosmetics/personal care products with the respective mechanisms of action. Likewise, in vitro and in vivo efficacy tests were discussed concerning the antipollution claim substantiating.
\end{abstract}

Keywords: Active ingredients. Antipollution. Cosmetics. Efficacy tests.

\section{INTRODUCTION}

The population living urban lifestyles continues to grow around the globe, and they are direct exposed to the pollution caused by vehicle fumes, industry, cigarette smoke and others. The primary pollutants are divided in two main groups: particulate matter (PM) that could also have polyaromatic hydrocarbons (PAHs), and toxic gases, like $\mathrm{CO}_{2}, \mathrm{CO}, \mathrm{SO}_{2}, \mathrm{NO}, \mathrm{NO}_{2}$ and other nitrogen oxides ( $\mathrm{NOx}$ ) (Portugal-Cohen et al., 2017). The skin, the outermost barrier of the body, is sensitive to these pollutants and it is frequently exposed to the environment. This is of major concern, since one of the skin main function is to protect the organism from such damaging substances. Pollution can cause dermatological hazard effects, like inflammation,

\footnotetext{
*Correspondence: A. R. Baby. Departamento de Farmácia, Faculdade de Ciências Farmacêuticas, Universidade de São Paulo. Av Prof. Lineu Prestes, 580, Bl. 15, 05508-900, São Paulo/SP, Brazil. Tel: +55 11 3091-3668. E-mail: andrerb@usp.br

$\S$ These authors contributed equally to this review work.
}

oxidative stress and metabolic impairments, and could also generate cancer, which might be amplified by the deleterious synergy of the sun, particularly UVA (Marrot, 2017).

Nowadays, the mechanisms understanding the cutaneous effects of pollutants continue unclear. However, its impact on the worldwide population has been reported in the last decade. Current research works in populous countries, as Mexico and China, indicated that exposure to pollution could affect sebum composition, stratum corneum quality and, also, intensify the signs of skin aging, such as pigmented spots and wrinkles. The skin is the main defense barrier against environmental agents and it is daily exposed to air pollutants that can be absorbed and cause toxic effects. The stratum corneum (SC) is the outer layer of the skin and represents the primary barrier to external agents. SC is composed of a compressed fusion of keratinized cells surrounded by an extracellular lipid matrix, arranged in a "brick and mortar" model. The "bricks" are composed of keratinocytes and "mortar" by the expelled contents of the lamellar 
granules, including lipids and proteins. Penetration/ permeation through the skin is related to the integrity of the barrier function, anatomic place, age, cutaneous hydration properties and physicochemical characteristics of the contaminants. Consequently, children and patients with damaged skin barriers are often affected by dermal exposure considering the increased absorption of air pollution. Polycyclic aromatic hydrocarbons (PAHs), volatile organic compounds (VOCs) and particulate matter (PM) are significant air pollutants that can damage the skin. Simple daily activities can expose the skin to toxic pollutants. For example, products containing organic solvents, as paints and varnishes can generate VOCs. These agents increased the inflammatory reaction, inducing cancer lesions and atopic dermatitis in animal and in vitro models. Additionally, the action of this harmful agents can be amplified with the interaction of UV-light and cause oxidative skin damage (Kim, Cho, Park, 2016).

$\mathrm{PAH}$ is mainly produced by wood/oil burning and in all smoke emerging from the combustion of organic matter. Regarding the nature of PAHs to generate reactive oxygen species, it also can induce melanocyte proliferation. Furthermore, the association of UV-light and PAH provokes melanin synthesis in melanocyte, resulting in the formation of environment-induced lentigines. Several studies showed that exposure to PAHs is associated with a development of skin cancer. Topical contact of mixtures of PAHs intensifies the frequency of skin cancers, such as papilloma, carcinoma, and squamous cell carcinoma. Daily a human can absorb up to $3.7 \mathrm{mg}$ of PAH and interestingly the primary exposure source of PAH contamination in human is food (smoked meat) and diet (Marrot, 2017; Soeur et al., 2017).

PM is the most harmful component of air pollution. It is generated by factories, power plants, incinerators, cars, construction industry, and fires. PM has a small size, few microns, and often includes mineral components, various metals which can generate harmful effects on the skin. However, the impact of PM on skin has not yet been characterized, its transcutaneous penetration has been recently described and may be limited, as recent studies rejected the bioavailability of particles larger than $20 \mathrm{~nm}$. Additionally, the phototoxicity behave of PM was studied in vitro. In a Keratinocyte model, the PM was phototoxic from $25 \mathrm{mg} \cdot \mathrm{mL}^{-1}$. The UVA seemed to mostly contribute to this phototoxic process, probably by exciting few chemicals, particularly UVA-photo-reactive (Kim, Cho, Park, 2016; Soeur et al., 2017).

Human hair has long been used as a biological marker for assessment of environmental pollutants, toxins, drug abuse and exposure to pesticides. Damages caused by pollution nowadays are evidenced in the scalp and hair. Large suspended particle, small airborne particles, smoke and gaseous pollution settle on the scalp and hair causing irritation, dandruff, redness, faster exfoliation of outer layers of the scalp and more sensitivity leading psoriasis on prolonged exposure. In addition, damage like exposing inner layers of the fiber and dry frizzy hair (Bencko, 1995; Rajput, 2015).

Hair fiber may be divided in cuticles, cortex and medulla. The medulla is the innermost portion of hair shaft. The cortex gives the hair strength, flexibility, elasticity and color (due to natural and artificial pigments). The cortex is surrounded by a single layer of overlapping transparent, scalelike cells of cuticle, the external layer of the hair. Its core function is to protect the hair shaft against environmental and chemical damages. Adherence and the orientation of cuticle are responsible for surface properties such as brightness and resistance to combing (Dario, Baby, Velasco, 2015; Gama, Baby, Velasco, 2017).

The hair fiber nature attracts some substances found in the air pollution. Hair absorbs water under both liquid and steam form. Keratin may absorb up to $40 \%$ of its own weight in water. Hydration is favored by temperature increase, by $\mathrm{pH}$ changing and by all polar solvents, which break hydrogen bonds. Hydration changes the fiber elasticity. This absorption is followed by a swelling in the hair, with $15-10 \%$ increase in its thread diameter and 0.5 $1.0 \%$ in its length. Both absorption and swelling essentially depend on the medium $\mathrm{pH}$. Polar solvents have a similar effect on hair threads. Normally, the hair resistance to swelling is due to the existence of bonds maintaining the reticular integrity, which avoids the molecules penetration (Gama, Baby, Velasco, 2017).

This absorptive and swelling phenomenon may favor the penetration of certain organic molecules. When the hair fiber is not intact, the porosity can be affected. Some situations influence on porosity: alkaline $\mathrm{pH}$, over 8; high temperature; chemical processes, as permanent waving, discoloration, straightening, dyeing and air relative humidity (Dario, Baby, Velasco, 2015; Gama, Baby, Velasco, 2017). Specific strategies can protect the hair from environmental damage, among them: avoiding exposure to air pollutants, frequent scalp wash with mild shampoos, use of special antioxidant shampoos and the protection of the fiber with substances that act by reducing the porosity.

\section{Antipollution active ingredients and mechanisms of action}

Skin naturally protects itself from pollutants at some extent by pathways of the immune system cells, 
however, prolonged and repetitive daily exposure to high levels of pollutants may impair the protective mechanisms. Some pollutants (e.g., PAHs) that can easily penetrate through the skin barrier still can induce damage even without percutaneous penetration to deeper skin layers via signal transduction mechanism (Valacchi et al., 2002). For that reason, daily application of skincare products that work as an effective shield against polluting agents are required to maintain skin balance. Antipollution formulations comprise mainly film formers and antioxidants designed to improve skin barrier function by physically shielding the skin and scavenging the oxidative pollutants. Cosmetic ingredients may either prevent the contact between skin and pollutants or start biochemical processes to reduce the oxidative primary and secondary products. It is recommended to design a formulation to achieve both goals. The active molecules can play a preventive role when blocking pro-inflammatory membrane signaling pathways like Keap1-Nfr2 and IKB-NFKB (Tanaka et $a l ., 2010)$. It can immediately reduce short-term health damage caused by inflammation factors, such as COX and interleukins. Other signaling pathways can be upregulated increasing cell differentiation like NOTCH1 and WNT (Wang et al., 2011) or improving xenobiotics metabolization like AhR (Jux et al., 2011). Multipurpose treatment strategies that combine biological and physical defense against contemporary pollution agents are more effective on both short and long-term skin damage.

Besides the use of specific antipollution treatment, there are general recommendation measures that can protect the skin against pollution-induced damage such as using rinse-off products (e.g. shower gel) to clean off pollution over the skin; sunscreens to absorb/scatter UV radiation and to prevent photo-reactive compounds responding on UV exposure; emollients to preserve and restore skin barrier function and the avoidance of over washing the skin, preventing the damage of the natural, cutaneous protective barrier (Krutmann et al., 2014).

Hair and scalp are also affected by the excessive exposure to pollutants, resulting in a dull, dry and lifeless appearance. Several types of pollutants show an adhesive property to hair fibers through adsorption and it can be used as an indicator of human exposure to pollution (Nakao et al., 2002). Antipollution hair cosmetics work through film forming and anti-adhesive effects. The film blocks pollutant particles adsorption and can be removed easily after rinsing (Blosl, Ott, Schacht, 2017). Table I shows an overview of the main active compounds and their mechanisms of action as antipollution agents.

\section{In vitro antipollution efficacy tests}

To better understand the different mechanisms that the pollutants have on cutaneous tissue, numerous in vitro studies have been made, mainly with human cell culture. In vitro human cell models are a representation of various cell types, derived by its embryological origin or specific tissue or organ (Alfaro-Moreno et al., 2008). The advantage is that these kind of cells are a representation of cell types that may be of interest and it is readily available for detailed mechanistic investigations, avoiding speciesto-species extrapolations, since it is derivate from human cells (Jia, Wang, Liu, 2017). Thus, they have demonstrated susceptibility to the toxic effects generated by environmental air pollutants, mimicking the human skin, and so being an interesting model (Cotovio et al., 2001).

Cotovio et al. (2001) exposed cultured immortalized human keratinocytes and a reconstructed human epidermis to $10 \mathrm{ppm}$ ozone and monitored the oxidative stress. They employed fluorescence intensity as an indicator of the extent of oxidative stress. Their results proved that there was a positive correlation between these factors in both models exposed to ozone. These results led them to investigate the protective potential of products like vitamin $\mathrm{C}$, a thiol derivative ( $\mathrm{N}$-acetyl cysteine) and a green tea extract. Reduced fluorescence levels measured in the keratinocytes and reconstructed epidermis compared to non-protected skin cells were observed; therefore, they were able to confirm that all samples were efficient in preventing ozone-induced cellular oxidative damage.

Duche, Cotovio, Catroux (2004) proposed the use of ellagic acid, a polyphenol, as a topical cosmetic antipollution agent. Using a monolayer culture of human keratinocytes, they proved that ellagic acid had cytoprotective and antioxidant effects against the atmospheric pollutant, ozone and combustion residues. Heavy metals and PAHs penetrate keratin proteins (like the hair and skin) and induce oxidative stress and cell apoptosis - not to mention the carcinogenic effects that PAHs have. They tested how well ellagic acid traped PAHs and heavy metals with a series of formulations, containing distinct concentrations of ellagic acid. The outcomes of these tests were: following pretreatment with ellagic acid, binding of PAHs to keratinocytes decreased, cell viability after exposure to the heavy metal cadmium chloride increased, and ozone-induced stress decreased (measurement of fluorescence in the keratinocytes) (Duche, Cotovio, Catroux, 2004).

Biatry (2002) also discussed a compound that could be employed in a cosmetic product as an antipollution agent to protect keratin materials. Emulsions of phytantriol, an 
TABLE I - Antipollution skin/hair treatments

\begin{tabular}{|c|c|c|c|}
\hline Active compound & Mechanism & $\begin{array}{c}\text { Potential antipollution } \\
\text { effect }\end{array}$ & References \\
\hline Dead Sea mineral-rich water & $\begin{array}{l}\text { Reduce UVB irradiation } \\
\text { induced cell apoptosis in } \\
\text { the epidermis of skin organ } \\
\text { cultures and reduce pro- } \\
\text { inflammatory cytokine, tumor } \\
\text { necrosis } \alpha(\mathrm{TNF} \alpha) \text { secretion }\end{array}$ & $\begin{array}{l}\text { Reduce inflammation marker } \\
\text { interleukin } 1 \alpha(\mathrm{IL}-1 \alpha) \text { when } \\
\text { applied before heavy metal } \\
\text { and atmospheric particulate } \\
\text { matter to in vitro human } \\
\text { skin models based on } \\
\text { reconstructed epidermis }\end{array}$ & $\begin{array}{l}\text { Wineman et al., 2012; } \\
\text { Portugal-Cohen et al., } 2017\end{array}$ \\
\hline $\begin{array}{l}\text { High molecular } \\
\text { polysaccharides }\end{array}$ & $\begin{array}{c}\text { Shield the skin/hair } \\
\text { by physical barrier to } \\
\text { atmospheric pollution and } \\
\text { UV radiation }\end{array}$ & & $\begin{array}{l}\text { Portugal-Cohen et al., 2017; } \\
\text { Wei et al., } 2009\end{array}$ \\
\hline Chelating molecules & Heavy metal-scavenging & $\begin{array}{c}\text { Reduce heavy metals } \\
\text { availability by forming } \\
\text { complexes }\end{array}$ & $\begin{array}{c}\text { Pelletier, Catroux, 2002; } \\
\text { Duche, Cotovio, Catroux, } \\
2004 \\
\end{array}$ \\
\hline $\begin{array}{l}\text { Fermentation products } \\
\text { (ectoin and hydroxiectoin) }\end{array}$ & $\begin{array}{c}\text { Regulate osmotic and } \\
\text { oxidative cell pathways }\end{array}$ & $\begin{array}{l}\text { Reduce UVA damage and } \\
\text { mitochondrial DNA mutation }\end{array}$ & $\begin{array}{c}\text { Buenger, Driller, 2004; Graf } \\
\text { et al., } 2008\end{array}$ \\
\hline Peptides & $\begin{array}{l}\text { Play an important role in } \\
\text { antioxidant cellular system } \\
\text { and skin hydration }\end{array}$ & $\begin{array}{l}\text { Reduce the levels of reactive } \\
\text { oxygen species (ROS) and } \\
\text { DNA, protein, and lipid } \\
\text { damage in keratinocytes } \\
\text { subjected to solar-simulating } \\
\text { UV oxidative stress }\end{array}$ & $\begin{array}{l}\text { Lintner, 2003; Catroux, } \\
\text { Cotovio, Duche, 2004; } \\
\text { Markova et al., } 2009\end{array}$ \\
\hline Plant extracts & $\begin{array}{c}\text { Flavonoids and anthocyanins } \\
\text { play an important role } \\
\text { in antioxidant pathways, } \\
\text { saponins support skin } \\
\text { autophagy } \\
\end{array}$ & $\begin{array}{c}\text { Reduce ROS levels and } \\
\text { promote cell autophagy when } \\
\text { damaged }\end{array}$ & $\begin{array}{c}\text { Hocquaux, Loing, Bedos, } \\
\text { 2015; Lintner, 2003; Sawa et } \\
\text { al., } 1999\end{array}$ \\
\hline Skin/hair conditioning agents & Improve skin/hair hydration & Improve skin/hair barrier & Biatry, 2002; Mausner, 1996 \\
\hline UVA and UVB filters & $\begin{array}{l}\text { Absorb/scatter UV radiation } \\
\text { and prevent the formation of } \\
\text { photoreactive compounds }\end{array}$ & $\begin{array}{l}\text { Reduce photoactivation of } \\
\text { pollutants and ROS formation }\end{array}$ & $\begin{array}{l}\text { Mausner, 1996; Fu et al., } \\
2012\end{array}$ \\
\hline
\end{tabular}

alcohol commonly found in cosmetics as a humectant, were applied to reconstructed-skin epidermal samples in order to assess in vitro its efficacy as an anti-pollutant. Combustion residue particles were $\mathrm{C}-14$ radiolabeled and also applied to the samples. After washing and then quantifying the amount of any remaining particles, it was revealed that phytantriol limited the penetration of combustion residues in skin cells.

Portugal-Cohen et al. (2017), using in vitro human skin models based on reconstructed epidermis, which exhibited normal barrier functions (presence of well-differentiated SC), evaluated the protection of two products applied alone or in combination, Dead Sea minerals (Dead Sea mineral-rich water - DSW) and anionic polysaccharide (PS), against mixture of pollutants (MOP) containing heavy metals / atmospheric particulate matter and ozone. The authors tested the levels of prostaglandin E2 (PGE2) and IL-1 $\alpha$, two inflammation markers. Their results found that, when DSW and PS were combined, they had the potential to inhibit PGE2 and IL-1 $\alpha$, being a model candidate for urban pollution protection

A research performed by Qiao et al. (2017) evaluated the hazard effects of SRM1649b, a standard reference material of urban air pollution particulate matters which contains a wide variety of PAHs, using human keratinocytes $(\mathrm{HaCaT})$ and normal human dermal fibroblasts (NHDF) cultures. The authors found that SRM1649b induced cell aging through growth inhibition, apoptosis and cell cycle G1 phase arrest. 
Soeur et al., (2017) using normal human epidermal keratinocytes (NHEK) and reconstructed skin model, measured the biological impact of pollutants (PM, PAH and PM extract) exposed to or daily UV (d-UV) wavelengths range $(300-400 \mathrm{~nm})$, which contained UVB radiation and the entire UVA band (UVA1 + UVA2), or UVA1 radiation $(350-400 \mathrm{~nm})$. The UVA1 had a phototoxic influence on the samples and it was equal or greater than the effect produced by d-UV. PAHs were phototoxic at nanomolar concentrations, concluding that only traces of PAH were enough to produce a high cellular stress, if combined with UVA1 exposure (Soeur et al., 2017).

\section{Antipollution efficacy assessment by in vivo methods}

Currently, mostly due to scarcity of scientific evidence, there are no established guidelines currently available for protecting the skin against air pollution (Mancebo, Wang, 2015). Nevertheless, cosmetic products presently available in the market tackle the effect of pollution in one or several of the following manners (Valacchi et al., 2012):

- Boost skin barrier structure and function.

- $\quad$ Provide topical antioxidants and decrease oxidative stress and inflammation.

- Decrease deposition of pollutants on skin by cleansing or exfoliation.

- $\quad$ Protect skin from harmful UV radiation, since it exacerbates the effect of the other environmental pollutants.

- $\quad$ Regulate melanogenesis.

- $\quad$ Promote synthesis of fibrous proteins in the dermis.

Skin barrier function is most commonly assessed in vivo through measurements of transepidermal water loss (TEWL) (Lotte et al., 1987; Pinnagoda et al., 1990). Nevertheless, poor correlations between damage inflicted to the skin and changes in TEWL values have often been reported in the literature (Bashir et al., 2001; Chilcott et al., 2002; Chilcott et al., 2007; Rosado, Pinto, Rodrigues, 2009), and "dynamic" strategies using TEWL data have been developed to improve the sensitivity of the methodology (Berardesca et al., 1990; Berardesca, Herbst, Maibach, 1993; Piérard-Franchimont et al., 1995; Rosado, Pinto, Rodrigues, 2005; Pinto et al., 2011). The impact of urban particulate pollution on skin barrier function and the subsequent drug absorption was assessed in vivo using the pig model (Pan et al., 2015). In this study, heavy metals (1648a) and PAHs (1649b) were used as pollutant models to treat the skin, and it was found that the latter significantly disrupted the TEWL by 2 -fold compared to a PBS control.

The efficacy of antioxidants is more often assessed in vitro, for instance by DPPH assay, although a few in vivo methodologies have been developed (Ratz-Lyko, Arct, Pytkowska, 2012). EPR spectroscopy and imaging (EPRI) of spin labels allow measurement of the kinetics and the mapping of the spatial distribution of free radicals in biological systems, thus allowing indirect evaluation of cosmetics antioxidant capacity (He et al., 2004). An interesting approach to efficacy testing of antioxidants was developed using the methyl nicotinate micro-inflammatory model (Vertuani et al., 2003). In the experiment, the skin was exposed to this vasodilator, and then it was deposited on a preparation containing antioxidants (vitamin $\mathrm{C}$ and E). Protective effects of the antioxidant substance were determined using the DermAnalyzer system, and the results of measurements were validated using standard skin measuring instruments: chromameter (assessing the color of the skin and the erythema through it's a* parameter), laser Doppler (for measuring perfusion) and TEWL. The methodology was further developed in another study assessing the antioxidant capacity of UV filters containing rutin (Oliveira et al., 2016).

A research group has advocated the oxidization of squalene, a human skin lipid, as a marker of environmental pollution studies (Pham et al., 2015). The squalene (per) oxidization process generates molecules that negatively impact the skin, thus, preventing such events can be a goal of topically applied antipollution preparations, mainly those containing antioxidants. An in vivo procedure to assess efficacy of such formulations was suggested, where, after application of the products, the forehead (or back) of subjects is exposed to low doses of UVA-visible rays, at the end of which sebum is collected and quantification of the possible different amount of (per)oxidized products present is conducted.

In a recent study, a pollution model to mimic particulate matter trapped in sebum and oils as a surrogate for dirty, polluted skin was developed, aiming to evaluate the cleansing efficacy/protective action of two different procedures against particulate pollution trapped in human sebum: a sonic brush vs. manual cleansing (Peterson et al., 2017). The pollution model consists of atmospheric particulate matter/pollution combined with grease/oils typical of human sebum. This mixture was applied to the cheek of human volunteers and the efficacy of the two cleaning protocols was compared using photography and imaging analysis.

Finally, researchers should take into account, as in any other in vivo efficacy study, that the panel of volunteers that 
is gathered to establish efficacy of antipollution cosmetics has to be judiciously selected. It has been suggested that the adverse effects of pollution particles are most prominent in susceptible subjects, particularly the elderly and patients with cardiopulmonary diseases (Huang, Ghio, 2009). Researchers have found that young and old mice exposed to either $\mathrm{O}_{3}$ or cigarette smoke have different oxidative stress and inflammatory marker responses (Lim et al., 2006; Fortino et al., 2007). In humans, it is known that elderly individuals have higher levels of both oxidative stress and inflammatory markers (Harman, 2009).

\section{CONCLUSIONS}

Considering the cutaneous tissue the largest organ of the human body and its direct and usual exposition to environmental pollutants (UV radiation, PAHs, nitogen oxides, ozone and cigarette smoke, amongst others), the cosmetic and personal care products claiming antipollution action are of utmost relevance to be deeply investigated, achieving safety profile and notorious efficacy. According to a multipurpose/multifunction characteristic of these active ingredients and finished products, complementing methods (efficacy tests) are required to entirely determine the protection and benefits from antipollution cosmetics. Yet, there is still much to be done to establish methodologies concerning the in vivo assessment of skin protection against pollution, even though a few interesting studies in this area can already be found in the literature.

\section{ACKNOWLEDGMENTS}

Authors greatly acknowledge the funding from FAPESP (2016/24360-4) and CAPES scholarship.

\section{REFERENCES}

Alfaro-Moreno E, Nawrot TS, Vanaudenaerde BM, Hoylaerts MF, Vanoirbeek JA, Nemery B, et al. Co-cultures of multiple cell types mimic pulmonary cell communication in response to urban PM10. Eur Respir J. 2008;32(5):1184-1194.

Bashir SJ, Chew AL, Anigbogu A, Dreher F, Maibach HI. Physical and physiological effects of stratum corneum tape stripping. Skin Res Technol. 2001;7(1):40-8.

Bencko V. Use of human hair as a biomarker in the assessment of exposure to pollutants in occupational and environmental settings. Toxicology. 1995;101(1-2):29-39.
Berardesca E, Fideli D, Gabba P, Cespa M, Raggiosi G, Maibach HI. Ranking of surfactant skin irritancy in vivo in man using the plastic occlusion stress test (POST). Contact Dermatitis. 1990;23(1):1-5.

Berardesca E, Herbst R, Maibach H. Plastic occlusion stress test as a model to investigate the effects of skin delipidization on the stratum corneum water holding capacity in vivo. Dermatology. 1993;187(2):91-4.

Biatry B. Use of phytanetriol as an anti-pollution agent, in particular in a cosmetic composition. Patent No. 20020048593. L'Oreal;2002.

Blosl N, Ott R, Schacht K. Efficient hair protection - the multifunctional silk polypeptide as new and promising strategy against pollution. Sofw J Home Personal Care Ingred Formul. 2017;143(7/8):42-45.

Buenger J, Driller H. Ectoin. an effective natural substance to prevent UVA-induced premature photoaging. Skin Pharmacol Physiol. 2004;17(5):232-237.

Catroux P, Cotovio J, Duche D. Use of ergothioneine and/ or its derivatives as an anti-pollution agent. Patent No. $20040047823 ; 2004$.

Chilcott RP, Dalton CH, Emmanuel AJ, Allen CE, Bradley ST. Transepidermal water loss does not correlate with skin barrier function in vitro. J Investig Dermatol. 2002;118(5):871-5.

Chilcott RP, Dalton CH, Ashley Z, Allen CE, Bradley ST, Maidment MP, et al. Evaluation of barrier creams against sulphur mustard: (II) In vivo and in vitro studies using the domestic white pig. Cutaneous Ocular Toxicol. 2007;26(3):23547.

Cotovio J, Onno L, Justine P, Lamure S, Catroux P. Generation of oxidative stress in human cutaneous models following in vitro ozone exposure. Toxicol In Vitro. 2001;15(4-5):357-362.

Dario MF, Baby AR, Velasco MV. Effects of solar radiation on hair and photoprotection. J Photochem Photobiol B Biol. 2015;153:240-246.

Duche D, Cotovio J, Catroux P. Use of ellagic acid as an antipollution cosmetic agent. Patent No. US20040013696 A1. 2004.

Fortino V, Maioli E, Torricelli C, Davis P, Valacchi G. Cutaneous MMPs are differently modulated by environmental stressors in old and young mice. Toxicol Lett. 2007;173(2):73-79. 
Fu P, Xia Q, Sun X, Yu H. Phototoxicity and environmental transformation of Polycyclic Aromatic Hydrocarbons (PAHs) - light-induced reactive oxygen species, lipid peroxidation, and DNA damage. J Environ Sci Health C Environ Carcinog Ecotoxicol Rev. 2012;30(1):1-41.

Gama RM, Baby AR, Velasco MV. In vitro methodologies to evaluate the effects of hair care products on hair fiber. Cosmetics. 2017;4(1):2.

Graf R, Anzali S, Buenger J, Pfluecker F, Driller H. The multifunctional role of ectoine as a natural cell protectant. Clin Dermatol. 2008;26(4):326-333.

Harman D. Origin and evolution of the free radical theory of aging: a brief personal history, 1954-2009. Biogerontology. 2009;10(6):773-81.

He G, Kutala VK, Kuppusamy P, Zweier JL. In vivo measurement and mapping of skin redox stress induced by ultraviolet light exposure. Free Radical Biol Med. 2004;36(5):665-72.

Hocquaux M, Loing E, Bedos P. Compounds, use thereof in cosmetic and cosmeceutic applications, and compositions comprising same. Patent No. 9115176. Lucas Meyer Cosmetics Canada Inc; 2015.

Huang Y-CT, Ghio AJ. Controlled human exposures to ambient pollutant particles in susceptible populations. Environ Health. 2009;8:33.

Jia Y, Wang Q, Liu T. Toxicity research of PM2.5 compositions in vitro. Int J Environ Rese Public Health. 2017;14(3):232.

Jux B, Kadow S, Luecke S, Rannug A, Krutmann J, Esser C. The aryl hydrocarbon receptor mediates UVB radiation-induced skin tanning. J Invest Dermatol. 2011;131(1):203-210.

Kim KE, Cho D, Park HJ. Air pollution and skin diseases: Adverse effects of airborne particulate matter on various skin diseases. Life Sci. 2016;152:126-134.

Krutmann J, Liu W, Li L, Pan X, Crawford M, Sore G, Seite S. Pollution and skin: From epidemiological and mechanistic studies to clinical implications. J Dermatol Sci. 2014;76(3):163168.

Lim Y, Phung AD, Corbacho AM, Aung HH, Maioli E, Reznick AZ, et al. Modulation of cutaneous wound healing by ozone: Differences between young and aged mice. Toxicol Lett. 2006;160(2):127-134.
Lintner K. Cosmetic or dermopharmaceutical use of peptides for healing, hydrating and improving skin appearance during natural or induced ageing (heliodermia, pollution). Patent No. 6620419. Sederma; 2003.

Lotte C, Rougier A, Wilson D, Maibach HI. In vivo relationship between transepidermal water loss and percutaneous penetration of some organic compounds in man: effect of anatomic site. Arch Dermatol Res. 1987;279(5):351-356.

Mancebo SE, Wang SQ. Recognizing the impact of ambient air pollution on skin health. J Eur Acad Dermatol Venereol. 2015;29(12):2326-2332.

Markova NG, Karaman-Jurukovska N, Dong KK, Damaghi N, Smiles KA, Yarosh DB. Skin cells and tissue are capable of using l-ergothioneine as an integral component of their antioxidant defense system. Free Radic Biol Med. 2009;46(8):1168-1176.

Marrot L. Pollution and sun exposure: a deleterious synergy. Mechanisms and opportunities for skin protection. Curr Med Chem. 2017. Doi: 10.2174/0929867324666170918123907.

Mausner J. Anti-pollution cosmetic composition. Patent No. 5.571.503. Jack Mausner; 1996.

Nakao T, Aozasa O, Ohta S, Miyata H. Assessment of human exposure to PCDDs, PCDFs and Co-PCBs using hair as a human pollution indicator sample I: development of analytical method for human hair and evaluation for exposure assessment. Chemosphere. 2002;48(8):885-896.

Oliveira CA, Dario MF, Sarruf FD, Mariz IFA, Velasco MVR, Rosado C, et al. Safety and efficacy evaluation of gelatin-based nanoparticles associated with UV filters. Colloids Surf B Biointerfaces. 2016;140:531-537.

Pan TL, Wang PW, Aljuffali IA, Huang CT, Lee CW, Fang JY. The impact of urban particulate pollution on skin barrier function and the subsequent drug absorption. J Dermatol Sci. 2015;78(1):51-60.

Pelletier P, Catroux P. Leguminous extract heavy-metalscavenging anti-pollution agent. Patent No. 20020192178. L'Oreal; 2002.

Peterson G, Rapaka S, Koski N, Kearney M, Ortblad K, Tadlock L. A robust sebum, oil, and particulate pollution model for assessing cleansing efficacy of human skin. Int J Cosmetic Sci. 2017;39(3):351-354. 
Pham DM, Boussouira B, Moyal D, Nguyen QL. Oxidization of squalene, a human skin lipid: a new and reliable marker of environmental pollution studies. Int J Cosmetic Sci. 2015;37(4):357-365.

Piérard-Franchimont C, Letawe C, Goffin V, Piérard GE. Skin water-holding capacity and transdermal estrogen therapy for menopause: a pilot study. Maturitas. 1995;22(2):151-154.

Pinnagoda J, Tupker RA, Agner TSJ, Pinnagoda J, Tupker RA, Agner T, Serup J. Guidelines for transepidermal water loss (TEWL) measurement: A report from the standardisation group of the European Society of Contact Dermatitis. Contact Dermatitis. 1990;22(3):164-172.

Pinto P, Rosado C, Parreirão C, Rodrigues LM. Is there any barrier impairment in sensitive skin?: a quantitative analysis of sensitive skin by mathematical modeling of transepidermal water loss desorption curves. Skin Res Technol. 2011;17(2):181-5.

Portugal-Cohen M, Oron M, Cohen Dror, Ma'or Z. Antipollution skin protection - a new paradigm and its demonstration on two active compounds. Clin Cosmet Investig Dermatol. 2017;10:185-193.

Qiao Y, Li Q, Du HY, Wang QW, Huang Y, Liu W. Airborne polycyclic aromatic hydrocarbons trigger human skin cells aging through aryl hydrocarbon receptor. Biochem Biophys Res Commun. 2017;488(3):445-452.

Rajput R. Understanding hair loss due to air pollution and the approach to management. Hair Ther Transplant. 2015;5:133.

Ratz-Lyko A, Arct J, Pytkowska K. Methods for evaluation of cosmetic antioxidant capacity. Skin Res Technol. 2012;18(4):421-30.

Rosado C, Pinto P, Rodrigues LM. Modeling TEWL-desorption curves: a new practical approach for the quantitative in vivo assessment of skin barrier. Experimental Dermatology. 2005;14(5):386-90.

Rosado C, Pinto P, Rodrigues LM. Assessment of moisturizers and barrier function restoration using dynamic methods. Skin Res Technol. 2009;15(1):77-83.
Sawa T, Nakao M, Akaike T, Ono K, Maeda H. Alkylperoxyl Radical-Scavenging Activity of Various Flavonoids and Other Phenolic Compounds: Implications for the AntiTumor-Promoter Effect of Vegetables. J Agric Food Chem. 1999;47(2):397-402.

Soeur J, Belaïdi JP, Chollet C, Denat L, Dimitrov A, Jones C, et al. Photo-pollution stress in skin: Traces of pollutants (PAH and particulate matter) impair redox homeostasis in keratinocytes exposed to UVA1. J Dermatol Sci. 2017;86(2):162-169.

Tanaka K, Asamitsu K, Uranishi H, Iddamalgoda A, Ito K, Kojima $\mathrm{H}$, et al. Protecting skin photoaging by NF-kappaB inhibitor. Curr Drug Metab. 2010;11(5):431-5.

Valacchi G, van der Vliet A, Schock BC, Okamoto T, Obermuller-Jevic U, Cross CE, Packer L. Ozone exposure activates oxidative stress responses in murine skin. Toxicology. 2002;179(1-2):163-170.

Valacchi G, Sticozzi C, Pecorelli A, Cervellati F, Cervellati C, Maioli E. Cutaneous responses to environmental stressors. Ann New York Acad Sci. 2012;1271(1):75-81.

Vertuani S, Ziosi P, Solaroli N, Buzzoni V, Carli M, Lucchi $\mathrm{E}$, et al. Determination of antioxidant efficacy of cosmetic formulations by non-invasive measurements. Skin Res Technol. 2003;9(3):245-53.

Wang R, Ahmed J, Wang G, Hassan I, Strulovici-Barel Y, Hackett N R, et al. Down-regulation of the canonical Wnt $\beta$-catenin pathway in the airway epithelium of healthy smokers and smokers with COPD. PLoS One. 2011;6(4):e14793.

Wei X, Liu Y, Xiao J, Wang Y. Protective effects of tea polysaccharides and polyphenols on skin. J Agric Food Chem. 2009;57:7757-7762.

Wineman E, Portugal-Cohen M, Soroka Y, Cohen D, Schlippe $\mathrm{G}$, Voss W, et al. Photo-damage protective effect of two facial products, containing a unique complex of Dead Seaminerals and Himalayan actives. J Cosmet Dermatol. 2012;11(3):183-92. 